Rev. Latinoam. Psicopat. Fund., São Paulo, v. 12, n. 4, p. 759-765, dezembro 2009

\title{
Passado e presente na psicopatologia da paranoia
}

Ana Maria Galdini Raimundo Oda

Este artigo comenta um ensaio do médico brasileiro Raimundo NinaRodrigues, publicado em 1902, sobre o diagnóstico e a psicopatologia da paranoia, bem como de suas relações com o chamado atavismo psíquico.

Palavras-chave: Raimundo Nina-Rodrigues, paranoia, atavismo psíquico, história da psicopatologia 
Em 1902, Raimundo Nina-Rodrigues (1862-1906) publicou “Atavisme psychique et paranoïa" nos Archives d'Anthropologie Criminelle, de Criminologie et de Psychologie Normale et Pathologique. Como nos informa o autor, o artigo funcionaria como introdução ao vindouro ensaio "La paranoïa chez les nègres", impresso em 1903 na revista de Lyon. Somente em 2004, "A paranoia nos negros" foi publicado em português, na Revista Latinoamericana de Psicopatologia Fundamental, que agora faz o mesmo com "Atavismo psíquico e paranoia".

Pouco antes, em 1899, ele publicara o artigo "Métissage, dégénerescence et crime" nesse importante periódico, então codirigido pelo médico legista Alexandre Lacassagne e pelo jurista e sociólogo Gabriel Tarde, nomes associados à Criminologia francesa; os Archives de Lacassagne faziam contraponto à contemporânea revista de Cesare Lombroso, os Archives de Psychiatrie et d'Anthropologie Criminelle (Corrêa, 2008). As determinações biológicas e sociais do crime eram objeto de debate e fonte de controvérsias, e neste caloroso debate se insere o médico brasileiro.

Nina-Rodrigues partia do princípio que o comportamento criminoso e a paranoia tinham em comum o fato de serem manifestações de degenerescência mental; assim, dizia estar convicto de que "uma boa análise psicológica de certas anomalias mentais deve ajudar muito na resolução do problema psicológico do criminoso". Desta forma, lhe parecia adequado preceder seus estudos sobre a criminalidade dos negros brasileiros pelo estudo da paranoia nos mesmos. E, meticulosamente, antes do estudo da paranoia nos negros, julgara relevante revisar a polêmica sobre a definição da paranoia e, principalmente, suas igualmente controvertidas relações com o chamado atavismo psíquico.

Mas esta não é apenas uma ampla revisão teórica; como enfatiza o autor, toda sua argumentação crítica se apoia sobre conclusões de estudos clínicos, ou seja, psicopatológicos, muito detalhados - é uma característica sua, o apreço pela pesquisa "em campo", médica ou etnográfica. Com relação a esta última abordagem, referindo-se a "Mestiçagem, degenerescência e crime", Mariza Corrêa indica que ele marcava

a diferença de sua abordagem em relação a outras, sobre uma questão que era debatida sem fundamentação empírica. Desde seu posto de observação privilegiado, num país no qual a miscigenação era corrente, Nina-Rodrigues acreditou

1. O artigo foi traduzido por Mariza Corrêa e publicado em 2008: Nina-Rodrigues, Raimundo. Mestiçagem, degenerescência e crime. História, Ciências, Saúde - Manguinhos, v. 15, n. 4, p. 1151-1182, 2008. Disponível em: 〈http://www.scielo.br/pdf/hcsm/v15n4/14.pdf〉. 
poder apresentar uma proposta para a questão em debate, baseada numa pesquisa empírica. (Corrêa, 2008, p. 1100)

E, se a posição de Nina-Rodrigues é semelhante àquela de vários alienistas seus contemporâneos, adotando um paralelismo evolucionista na análise da psicopatologia dos povos primitivos ou não civilizados, com objetivo de validar universalmente certos construtos teóricos (Dalgalarrondo, 1996), suas observações clínicas e etnográficas lhe dão subsídios para questionar algumas ideias correntes, de certa forma tornando mais complexas as noções de inferioridade da raça negra e das consequências negativas da mestiçagem - o que não quer dizer, observe-se, que se afaste de sua posição racialista ou que ponha em questão a existência de uma ou de outra.

É desta posição que o médico brasileiro estabelece a interlocução com seus pares de outras terras, colocando-se em condição de igualdade quanto ao conhecimento teórico e com a vantagem da experiência prática, seja falando como médico legista, psicopatólogo ou antropólogo - visadas indissociáveis, para um criminologista de fins do XIX e inícios do século XX.

Uma discussão mais extensa sobre as diferentes concepções da paranoia será encontrada no texto de 1903 ("A paranoia nos negros"), pois o foco desse ensaio de 1902 é o atavismo. Em resumo, com respeito ao diagnóstico da paranoia, o autor diz que não acredita em tipos mórbidos fixos; afirma crer que as várias formas clínicas da paranoia teriam continuidade entre si, no espaço entre as duas formas extremas: de um lado, os delírios sistematizados e lentamente construídos e, de outro, os quadros súbitos, polimorfos, de marcha irregular e até mesmo casos sem delírio ou com delírio efêmero (Nina-Rodrigues, 2004 [1903]). ${ }^{2}$

No ensaio aqui republicado, Nina-Rodrigues discute com detalhes, e busca refutar sistematicamente, a famosa teoria do retorno atávico do paranoico ao funcionamento mental do homem primitivo, postulada pelos médicos italianos E. Tanzi e G. Riva e tomada por eles da formulação que Lombroso fizera para o seu "criminoso nato".

De início, destaca o que considera a "visão profunda" dos italianos sobre a paranoia, ou seja, a diferenciação de dois elementos distintos nela: o fundo degenerativo (constante) e a presença de delírio sistematizado (acidental ou eventual). Concorda com eles que os delírios sistematizados constituem um grupo sintomático, ao passo que a verdadeira paranoia é uma forma mórbida constitucional.

Porém, as concordâncias param por aí; a seguir, o leitor verá que Nina-Rodrigues tem como objetivo demonstrar que "a teoria dos ilustres alienistas é pouco precisa, escorregadia e algo confusa", quando afirmam que a patogênese da pa-

2. Veja-se também o artigo de Oda e Dalgalarrondo, 2004. 
ranoia decorre da regressão do doente a um funcionamento mental idêntico à do homem primitivo ancestral, o tal retorno atávico. Um dos argumentos dos médicos italianos é que o anacronismo seria a marca do delírio do paranoico atual, outro é que delírios e alucinações seriam fenômenos normais no homem primitivo ancestral ou mesmo entre as "raças inferiores" existentes naquele momento (negros e índios).

A isto se opõe nosso autor, elencando uma série de opiniões autorizadas (Krafft-Ebing, Magnan etc.) que indicavam o contrário, que as concepções delirantes costumavam provir das ideias dominantes em cada época. Também chama em seu auxílio as críticas às hipóteses de atavismo físico e de atavismo moral ou criminal (de Feré e Tarde, respectivamente); invoca o naturalista Haeckel e sua teoria da recapitulação, e também o embriologista M. Duval, para determinar o sentido biológico do termo atavismo. Autores como Griesinger, Ribot, Sergi, Meynert, Del Greco, Schule, Seglas, entre outros, se apresentam na discussão psicológica e psicopatológica, feita sobre a constituição do "eu" ("eu primitivo" e "eu segundo") ou do caráter, e sobre a evolução e dissolução psíquicas, na normalidade e na doença mental ou cerebral.

Para Nina-Rodrigues, o paranoico é um degenerado superior, cuja anomalia mental decorre da parada no desenvolvimento do caráter (ou personalidade) em suas fases iniciais, infantis, e que poderia se revelar clinicamente por simples desordens da conduta ou por delírios sistematizados específicos, de perseguição ou de grandeza.

Assim, ele conclui que não existiriam ideias atávicas na paranoia, mas um cérebro desorganizado e regredido, cujas funções psíquicas tinham sido muito prejudicadas pela desorganização degenerativa e que, portanto, teria a inteligência, o pensamento, o afeto e a vontade tornados mais primitivos, regredindo a modos de funcionamento correspondentes a camadas psíquicas mais antigas. No paranoico, o instinto de conservação retornaria a uma fase defensiva, ampliando os primordiais sentimentos de medo e de orgulho e obstruindo aqueles ligados à simpatia e à imitação, considerados mais evoluídos no processo de constituição mental individual.

Quanto à idade de início e marcha da enfermidade, pensa que a degenerescência do paranoico poderia manifestar-se desde a infância (a "paranoia originária" ou "sem delírio") ou, sendo relativamente compensada, manter-se em estado latente e se revelar apenas sob influência de abalos ou perturbações cerebrais, decorrentes de períodos críticos da evolução orgânica individual (puberdade, virilidade, menopausa etc.), bem como de emoções profundas (a "paranoia tardia").

Finalizando, cabe indicar uma ausência, ou talvez somente a aparência dela. Nina-Rodrigues cita extensamente autores cujas definições haviam sido retomadas e transformadas na grande síntese kraepeliniana (Bercherie, 1989), como Krafft-Ebing. Mas aqui não menciona Emil Kraepelin; no artigo que se segue, o 
de 1903, fará uma breve menção à "demência paranoide de Kraepelin", entretanto, sem estabelecer qualquer interlocução com o alienista alemão.

Deve-se recordar que, em 1902, Kraepelin já havia editado a conhecida sexta revisão do seu Tratado de psiquiatria, que é de 1899. Ali estabelece a diferenciação entre as doenças adquiridas (exógenas) e constitucionais (endógenas). A paranoia se define como doença endógena, separada de outras afecções que apresentavam apenas sintomas paranoides (Moreira e Peixoto, 2001, [1905]; Bercherie, 1989). Algo muito próximo da visão adotada por Nina-Rodrigues, de paranoia como doença constitucional, tomada de autores franceses, alemães e italianos, segundo cita.

A discussão sobre diagnóstico diferencial entre a paranoia e as síndromes paranoides aparece destacada no primeiro periódico brasileiro especializado em psiquiatria, surgido em 1905 e editado por Juliano Moreira e seu grupo de médicos do Hospício Nacional do Rio de Janeiro (Oda e Dalgalarrondo, 2001). Indica-se ali claramente a sua filiação à chamada escola alemã de Kraepelin (Moreira e Peixoto, 2001 [1905]). No entanto, é preciso pensar que essa autodeclarada filiação não excluía radicalmente outras "paternidades" de ideias psicopatológicas adotadas.

Afinal, talvez mesmo Kraepelin não fosse tão kraepeliniano assim; como analisa Paul Bercherie (1989), além de realizar a grande síntese das diversas contribuições de outros autores, a par de suas próprias, a cada versão revisada de seu Tratado, ele respondia a críticas à sua nosologia, de alguma maneira incorporando-as no processo de reformulação teórica constante a que se propusera.

Ao fim e ao cabo, franceses e alemães (e ainda ingleses, italianos, portugueses, espanhóis, norte-americanos e brasileiros) às vezes divergiam menos - ou eram menos originais - do que gostariam de admitir, e esse artigo de Nina-Rodrigues mostra como o discurso da ciência, produto da cultura, se constrói de conceitos que circulam e que são feitos e refeitos na teia da história.

\section{Referências}

BERCHERIE, P. Os fundamentos da clínica: história e estrutura do saber psiquiátrico. Tradução Vera Ribeiro. Rio de Janeiro: Jorge Zahar, 1989.

CorrêA, M. Nossos mulatos são mais exuberantes. História, Ciências, Saúde Manguinhos, Rio de Janeiro, v. 15, n. 4, p. 1099-1103, 2008. Disponível em: <http:// www.scielo.br/pdf/hcsm/v15n4/12.pdf>. Acesso em: 10 nov. 2009.

Dalgalarrondo, P. Civilização e loucura: uma introdução à história da etnopsiquiatria. São Paulo: Lemos, 1996. 
Moreira, J.; Peixoto, A. (1905). A paranoia e as síndromes paranoides. Revista Latinoamericana de Psicopatologia Fundamental, São Paulo, v. 4, n. 2, p. 134-167, jun. 2001. Disponível em: <http://www.fundamentalpsychopathology.org/art/jun1/ classicos.pdf>. Acesso em: 10 nov. 2009.

Nina-Rodrigues, R. (1902). Atavisme psychique et paranoïa. Archives d'Anthropologie Criminelle, de Criminologie et de Psychologie Normale et Pathologique, Lyon, ano 17, n. 102, p. 325-355, 1902. Disponível em: <http:// www.criminocorpus.cnrs.fr/ebibliotheque/ice/>. Acesso em: 10 nov. 2009.

. (1903). A paranoia nos negros: estudo clínico e médico-legal. Revista Latinoamericana de Psicopatologia Fundamental, São Paulo, v. 7, n. 2, p. 161-178, jun. 2004 (parte 1); v. 7, n. 3, p. 131-158, set. 2004 (parte 2); v. 7, n. 4, p. 217-239, dez. 2004 (parte 3). Disponível em: <http://www.fundamentalpsychopathology.org/art/jun4/ paranoia.pdf>. Acesso em: 10 nov. 2009.

. (1903). La paranoïa chez les nègres: étude clinique et médico-légale. Archives d'Anthropologie Criminelle, de Criminologie et de Psychologie Normale et Pathologique, Lyon, ano 18, n. 118, p. 609-651 e ano 18, n. 119, p. 689-714, 1903. Disponível em: <http://www.criminocorpus.cnrs.fr/ebibliotheque/ice/>. Acesso em: 10 nov. 2009.

Oda, A. M. G. R.; Dalgalarrondo, P. A paranoia, segundo Juliano Moreira e Afrânio Peixoto. Revista Latinoamericana de Psicopatologia Fundamental, São Paulo, v. 4, n. 2, p. 125-133, jun. 2001. Disponível em: <http://www.fundamentalpsychopathology. org/art/jun1/classicos.introd.pdf $>$. Acesso em: 10 nov. 2009.

; ____. Uma preciosidade da psicopatologia brasileira: a paranoia nos negros, de Raimundo Nina-Rodrigues. Revista Latinoamericana de Psicopatologia Fundamental, São Paulo, v. 7, n. 2, p. 147-160, jun. 2004. Disponível em: <http:// www.fundamentalpsychopathology.org/art/jun4/historia.pdf>. Acesso em: 10 nov. 2009.

\section{Resumos}

(Pasado y presente en la psicopatología de la paranoia)

Este artículo comenta un ensayo del médico brasileño Raimundo Nina-Rodrigues, publicado en 1902, sobre el diagnóstico y la sicopatología de la paranoia, así como sus relaciones con el llamado atavismo psíquico.

Palabras clave: Raimundo Nina-Rodrigues, paranoia, atavismo psíquico, historia de la psicopatología

(Passé et présent dans la psychopathologie de la paranoïa)

Cet article passe en revue un essai du médecin brésilien Raimundo Nina Rodrigues publié en 1902 sur le diagnostic et la psychopathologie de la paranö̈a, 
ainsi que leurs rapports avec ce qu'on appelle l'atavisme psychique.

Mots clés: Raimundo Nina-Rodrigues, paranoïa, atavisme psychique, histoire de la psychopathologie

(Past and present in the psychopathology of paranoia)

This article comments on an essay by the Brazilian physician Raimundo Nina Rodrigues, published in 1902, on the diagnosis and psychopathology of paranoia and its relationships with so-called psychic atavism.

Key words: Raimundo Nina-Rodrigues, paranoia, psychic atavism, history of psychopathology

Citação/Citation: OdA, A.M.G.R. Passado e presente na psicopatologia da paranoia. $R e$ vista Latinoamericana de Psicopatologia Fundamental, São Paulo, v. 12, n. 4, p. 759-765, dez. 2009.

Editor do artigo/Editor: Prof. Dr. Paulo Dalgalarrondo e Profa. Dra. Ana Maria G. Raimundo Oda.

Recebido/Received: 10.11.2009/ 11.10.2009 Aceito/Accepted: 13.11.2009 / 11.13.2009

Copyright: (C) 2009 Associação Universitária de Pesquisa em Psicopatologia Fundamental/ University Association for Research in Fundamental Psychopathology. Este é um artigo de livre acesso, que permite uso irrestrito, distribuição e reprodução em qualquer meio, desde que o autor e a fonte sejam citados/This is an open-access article, which permits unrestricted use, distribution, and reproduction in any medium, provided the original author and source are credited.

Financiamento/Funding: A autora declara não ter sido financiada ou apoiada/The author has no support or funding to report.

Conflito de interesses: A autora declara que não há conflito de interesses/The author declares that has no conflict of interest.

\section{Ana Maria Galdini Raimundo Oda}

Médica psiquiatra, com mestrado em Saúde Mental (1998) e doutorado em Ciências Médicas (2003) pela Universidade Estadual de Campinas - Unicamp (Campinas, SP, Brasil); tem experiência nas áreas de psiquiatria clínica e de saúde mental em saúde coletiva, e ainda em pesquisa em história da medicina, da psiquiatria e da psicopatologia; editora associada da $R e$ vista Latinoamericana de Psicopatologia Fundamental (seção História da Psiquiatria) e atual coordenadora do Departamento de História da Psiquiatria da Associação Brasileira de Psiquiatria; professora adjunta do Departamento de Medicina do Centro de Ciências Biológicas e da Saúde da Universidade Federal de São Carlos - UFSCar (São Carlos, SP, Brasil). Universidade Federal de São Carlos - CCBS - Departamento de Medicina Rodovia Washington Luis, Km 235 13565-905 São Carlos, SP, Brasil anaoda@ufscar.br 